EESTI NSV TEADUSTE AKADEEMIA TOIMETISED. XVII KOIDE

KEEMIA * GEOLOOGIA. 1968, Nr. 4

ИЗВЕСТИЯ АКАДЕМИИ НАУК ЭСТОНСКОЛ ССР. ТОМ ХVII Химия * ГЕОЛОгия. 1968, 스 4

К. ЛЭЭТС, А. КОГЕРМАН

\title{
ПОЛУЧЕНИЕ ГЕРАНИОЛА И ФАРНЕЗОЛА НА БАЗЕ ТЕЛОМЕРА ИЗОПРЕНА С ЕГО ГИДРОХЛОРИДАМИ
}

Терпеноидные спирты гераниол и фарнезол из-за своего приятного запаха уже давно применяются как душистые вещества. Так как до сих пор источником их получения былй дорогостоящие эфирные масла, то, естественно, внимание исследователей привлекли препаративные методы синтеза этих соединений из легкодоступного и дешевого сырья.

Ранее одним из нас сообщалось ['] о способе выделения геранилхлорида из фракции монотерпеновых хлоридов теломера изопрена с его гидрохлоридами, заключающемся в селективном превращении геранилхлорида в четвертичную соль аммония, и о получении из этой соли геранилацетата $\left[{ }^{2}\right]$ путем обработки ее с уксуснокислым калием по следующей схеме:

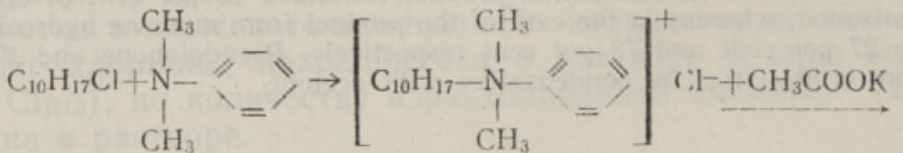

$$
\begin{aligned}
& \rightarrow\left[\begin{array}{c}
\mathrm{CH}_{3} \\
1 \\
\mathrm{C}_{10} \mathrm{H}_{17} \mathrm{~N}- \\
\frac{\mathrm{CH}}{\mathrm{CH}_{3}}
\end{array}\right]^{+} \text {OOCCH }_{3}^{-} \stackrel{110^{\circ} \mathrm{C}_{10} \mathrm{H}_{17} \mathrm{OOCCH}_{3}}{\rightarrow}
\end{aligned}
$$

Упомянутый способ ${ }^{[2]}$ в настоящей работе был подробно изучен с целью. разработки методов получения гераниола и фарнезола из продуктов теломеризации изопрена с его гидрохлоридами и определения изомерного состава получаемых продуктов.

Как известно, содержание геранилхлорида во фракции $\mathrm{C}_{10}$ теломера зависит главным образом от глубины теломеризации [3]. Поэтому мы провели указанным выше способом несколько синтезов гераниола, используя в качестве исходных веществ терпеновые фракции теломеров с различной глубиной теломеризации и, следовательно, с различным содержанием геранилхлорида. Во всех опытах определялась также зависимость чистоты и выхода гераниола от времени образования комплекса геранилхлорида с диметиланилином. Полученные после омыления ацетатов образцы гераниола анализировались газохроматографическим методом [4].

Қак видно из таблицы (см. экспериментальную часть), синтезированный из различных теломеров гераниол обладал чистотой не менее $97 \%$ и не требовал дополнительной очистки, причем чистота получае- 


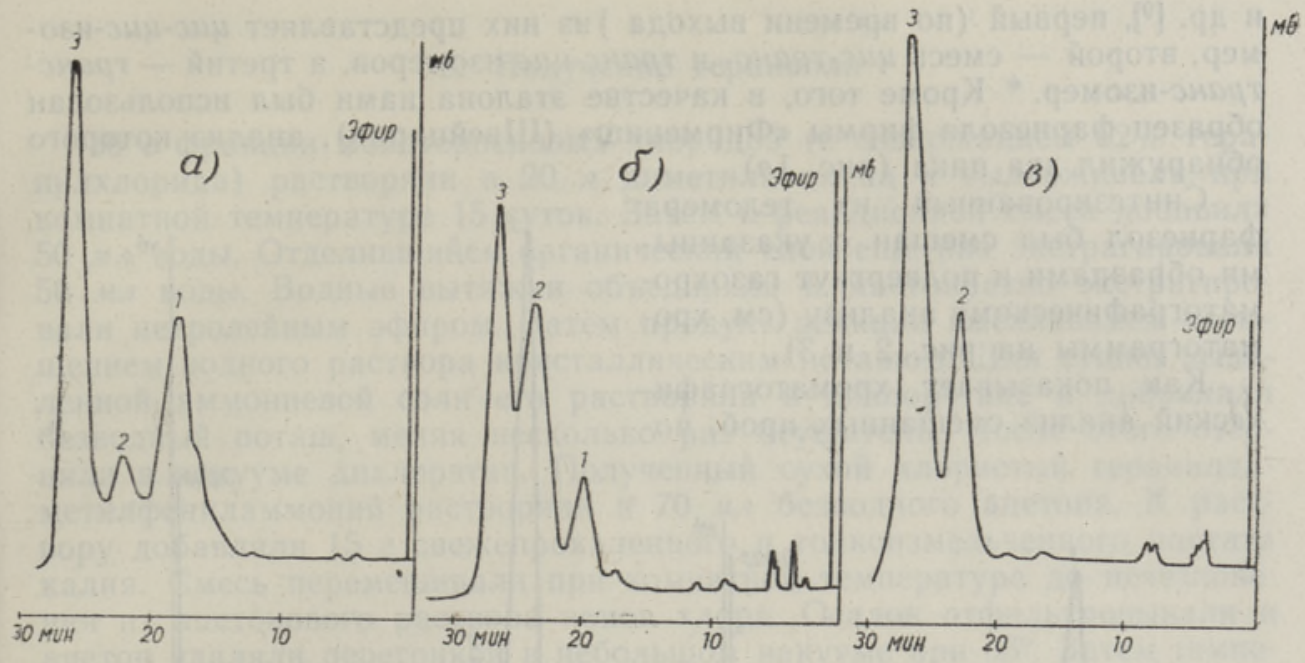

Рис. 1. Хроматограммы фарнезола, полученного из теломера $(a)$, синтезированного из линалоола (б) и фарнезола фирмы «Фирмениш» (в).

мого гераниола с уменьшением содержания геранилхлорида в исходной фракции заметно не уменьшалась. Не наблюдалось также заметного повышения содержания изомерных спиртов в продукте при увеличении времени образования соединения с диметиланилином. Интересно, что синтезированный гераниол не содержал цис-изомера - нерола. Из сннтетического гераниола был получен дифенилуретан, температура плавления которого равна описанной в литературе [5].

При реакции теломеризации изопрена с его гидрохлоридами наряду с основной фракцией монотерпеновых хлоридов образуется значительное количество сесквитерпеновых и политерпеновых хлоридов.

На базе фарнезилхлорида сесквитерпеновой фракции возможен синтез ценных парфюмерных продуктов. До сих пор единственной опубликованной работой, посвященной способам использования указанных хлоридов, является работа Е. Шварца и А. Петрова [6], которые изучали возможнссть прямого превращения их под действием уксуснокислого калия в ацетаты. Из продуктов омыления последних перегонкой в вакууме был выделен фарнезол. Однако ввиду сложности состава исходной фракции хлоридов вряд ли можно приписать выделенному продукту структуру вещества определенной чистоты.

Для получения фарнезола из фракции сесквитерпеновых хлоридов нами изучался способ, использованный для получения гераниола, описанный выше. Содержащая фарнезилхлорид фракция была выделена и обработана с диметиланилином по методике [7]. Для очистки полученной соли был разработан способ селективной экстракции 60\%-ным водным метанолом и петролейным эфиром. Выделенное и очнщенное соединение превращалось в ацетат, омылением которого спиртовой щелочью был получен синтетический фарнезол с физико-химическими константами, приведенными в экспериментальной части.

Полученный фарнезол исследовался газохроматографически. Было обнаружено три основных пика (рис. $1 a$ ). В качестве эталона был синтезирован образец фарнезола по методике [8], исходя из природного линалоола (рис. 1б). Как видно из газовой хроматограммы (рис. 1б), полученный изомер также содержал три изомера. По данным Р. Бэйтс 
и др. [9], первый (по времени выхода ) из них представляет цис-цицс-изомер, второй - смесь ццс-транс- и транс-цис-изомеров, а третий - транстранс-изомер. * Кроме того, в качестве эталона нами был использован образец фарнезола фирмы «Фирмениш» (Швейцария), анализ которого обнаружил два пика (рис. 1в).

Синтезированный из теломера фарнезол был смешан с указанными образцами и подвергнут газохроматографическому анализу (см. хроматограммы на рис. 2 и 3).

Как показывает хроматографический анализ смешанных проб, по-

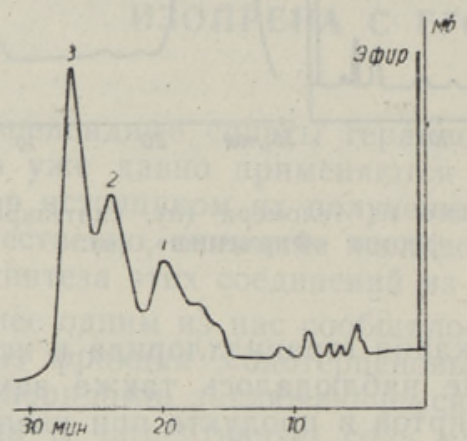

Рис. 2. Хроматограмма смешанной пробы $(1: 1)$ фарнезолов из теломера и из линалоола.

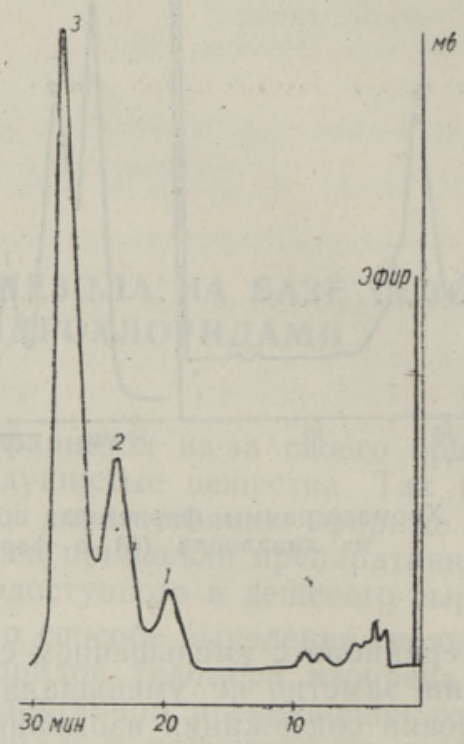

Рнс. 3. Хроматограмма смешанной пробы $(1: 1)$ фарнезола из теломера фирмы $\propto$ фирмениш».

лученный нами образец фарнезола существенно не отличается от синтетического фарнезола, полученного из линалоола, за исключением соотношения отдельных изомеров. Кроме того, полученный продукт обладает хорошими парфюмерными качествами.

\section{ЭКСПЕРИМЕНТАЛЬНАЯ ЧАСТЬ}

\section{1. Выделение моно- и сесквитерпеновых хлоридов}

В качестве исходного сырья использовали теломеры, полученные по методике, описанной в [3]. В опытах были использованы три различных теломера, полученных при глубине теломеризации 20; 44 и 62\% соответственно. Для получения фарнезола был взят первый из них.

Фракция хлоридов $\mathrm{C}_{10}$ была выделена из теломера вакуумной перегонкой при $65-90^{\circ}(2-3$ мм).

Остаток политерпеновых хлоридов был подвергнут азеотропной перегонке с перегретыми парами этиленгликоля при температуре в кубе $100^{\circ}$ и давлении $3-5$ мм рт. ст. [7].

Выход фракции $\mathrm{C}_{15}$ с содержанием $45 \%$ первичных аллильных ceсквитерпеновых хлоридов составил 15-16\% от исходного теломера.

* Номенклатура стереоязомеров фарнезола принята согласно Р. Бэйтс [ $\left.{ }^{9}\right]$. 


\section{2. Получение гераниола}

30 г фракции монотерпеновых хлоридов (с содержанием $62 \%$ геранилхлорида) растворяли в $20 \Omega$ диметиланилина и выдерживали при комнатной температуре 15 суток. Затем к реакционной смеси добавили 50 мл воды. Отделившийся органический слой еще раз экстрагировали 50 мл воды. Водные вытяжки объединяли и многократно экстрагировали петролейным эфиром. Затем продукт реакции высаливался насыщением водного раствора кристаллическим поташом. Для сушки выделенной аммониевой соли его растворяли в дихлорэтане и добавляли безводный поташ, меняя несколько раз осушитель. После этого отгоняли в вакууме дихлорэтан. Полученный сухой хлористый геранилдиметилфениламмоний растворяли в 70 мл безводного ацетона. К раствору добавляли 15 г свежепрокаленного и тонкоизмельченного ацетата калия. Смесь перемешивали при комнатной температуре до исчезновения из ацетонового раствора ионов хлора. Осадок отфильтровывали и ацетон удаляли перегонкой в небольшом вакууме при $35^{\circ}$. Затем температуру остатка повышали до $110^{\circ}$, углубляя вакуум до 10 мм, и отгоняли диметиланилин. Оставшийся в колбе сырой геранилацетат растворяли в петролейном эфире, промывали $2 \%$-ной серной кислотой, затем водой до нейтральной реакцин. После отгонки растворителя оставшийся в колбе сырой геранилацетат омыляли 0,5 н. метанольно-водным раствором $\mathrm{KOH}$ кипячением в течение четырех часов. Для нейтрализации избытка щелочи через реакционную смесь пропускали $\mathrm{CO}_{2}$, осадок отфильтровывали и промывали метанолом. Продукт разбавляли дву кратным количеством воды и извлекали петролейным эфиром. После сушки над сернокислым магнием растворители отгонялись в слабом вакууме и остаток перегонялся в вакууме.

Получено 6,85 г (выход $41 \%)$ гераниола с т. кип. $106-110^{\circ}(10$ мм), $n_{D}{ }^{20} 1,4771, d_{4}{ }^{20} 0,8832$.

Найдено \%: $\mathrm{C}_{10} \mathrm{H}_{17} \mathrm{OH}-98 \%$ (фталированием в пиридине).

Данные остальных опытов приведены в таблице.

\begin{tabular}{|c|c|c|c|c|c|c|c|c|}
\hline \multicolumn{4}{|c|}{ Загружено } & \multirow{4}{*}{$\begin{array}{l}\text { Молярное } \\
\text { соотно- } \\
\text { шение ди- } \\
\text { мєтилани- } \\
\text { лин : rера- } \\
\text { нилхлорид }\end{array}$} & \multirow{4}{*}{ 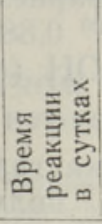 } & \multicolumn{3}{|c|}{ Выход гераниола } \\
\hline \multicolumn{3}{|c|}{$\begin{array}{c}\text { фракции монотерпеновых } \\
\text { хлоридсв }\end{array}$} & \multirow{3}{*}{$\begin{array}{c}\text { диметил- } \\
\text { анилина, } \\
2\end{array}$} & & & & & Содержа- \\
\hline \multirow[t]{2}{*}{2} & \multicolumn{2}{|c|}{$\begin{array}{l}\text { Содержание } \\
\text { геранилхлоридов }\end{array}$} & & & & e & 占总。 & $\begin{array}{l}\text { ниола в об- } \\
\text { разце, \% }\end{array}$ \\
\hline & $\%$ & 2 & & & & & & \\
\hline $\begin{array}{l}30,0 \\
30,0 \\
30,0 \\
40 \\
40 \\
40 \\
50 \\
50 \\
50\end{array}$ & $\begin{array}{l}62 \\
62 \\
62 \\
38 \\
38 \\
38 \\
24 \\
24 \\
24\end{array}$ & $\begin{array}{l}18,6 \\
18,6 \\
18,6 \\
15,2 \\
15,2 \\
15,2 \\
12,0 \\
12,0 \\
12,0\end{array}$ & $\begin{array}{l}21,0 \\
21,0 \\
21,0 \\
17 \\
17 \\
17 \\
14,7 \\
14,7 \\
14,7\end{array}$ & $\begin{array}{l}1,6 \\
1,6 \\
1,6 \\
1,6 \\
1,6 \\
1,6 \\
1,75 \\
1,75 \\
1,5\end{array}$ & $\begin{array}{r}7 \\
14 \\
30 \\
7 \\
15 \\
30 \\
7 \\
15 \\
30\end{array}$ & $\begin{array}{l}6,50 \\
6,85 \\
6,90 \\
4,70 \\
5,10 \\
5,11 \\
3,2 \\
3,3 \\
3,5\end{array}$ & $\begin{array}{l}39 \\
41 \\
42 \\
35 \\
38 \\
38 \\
30 \\
31,5 \\
35\end{array}$ & $\begin{array}{l}98,5 \\
98,5 \\
98,0 \\
98,5 \\
98,5 \\
97,5 \\
98,0 \\
97,0 \\
97,0\end{array}$ \\
\hline
\end{tabular}

Пр имечани е. Температура реакции $20-25^{\circ} \mathrm{C}$.

Температура плавления синтезированного из полученного образца гераниола $81-82^{\circ}$, дифенилуретана природного гераниола: $82^{\circ}$. 


\section{3. Получение фарнезола}

54 г фракции сесквитерпеновых хлоридов $\left(\mathrm{C}_{15}\right)$ (с содержанием первичного аллильного хлорида $45 \%$ ) растворяли в 36 г диметиланилина. После проведения реакции при комнатной температуре в течєние 30 суток смесь разбавляли петролейным эфиром и образовавшиєся четвертичные соли аммония растворили в $60 \%$-ном водном метаноле. Метанольную вытяжку многократно экстрагировали петролейным эфиром, до исчезновения запаха в вытяжке, и метанол отгоняли в небольшом вакууме при температуре бани не выше $35-40^{\circ}$. При насыщении оставшегося в колбе водного раствора кристаллическим поташом высаливалась четвертичная аммониевая соль. Водный слой отделяли, а продукт разбавляли равным по объему количеством дихлорэтана и сушили прокаленным поташом, меняя несколько раз осушитель. После добавки небольшого количества поташа растворители отгонялись вместе с остатками влаги в вакууме при температуре не выше $40^{\circ}$.

Выделенные соединения сесквитерпенового хлорида с диметиланилином растворяли в 200 мл безводного ацетона.

K раствору добавляли 14,5 г свежепрокаленного, тонкоизмельченного уксуснокислого калия. Смесь перемешивали при комнатной температуре до исчезновения из ацетонового раствора ионов хлора. Осадок отфильтровывали и промывали ацетоном. Промывной ацетон присоединяли к основному раствору. Затем ацетон удаляли отгонкой в небольшом вакууме. Остаток в колбе нагревали в более глубоком вакууме (5-10 мм) при температуре $110-115^{\circ}$. При этом отгонялся диметиланилин. После окончания выделения диметиланилина остаток охлаждали, разбавляли петролейным эфиром и промывали $5 \%$-ной $\mathrm{H}_{2} \mathrm{SO}_{4}$, затем раствором $\mathrm{NaHCO}_{3}$ и водой и высушивали над прокаленным поташом. Растворитель отгоняли и остаток омыляли 0,5 н. метанольно-водным раствором КОН кипячением на водной бане в течение 4 час. После охлаждения разбавляли водой и затем продукт экстрагировали эфиром. Әфирную вытяжку промывали водой до нейтральной реакции, высушивали над $\mathrm{MgSO}_{4}$ и эфир отгоняли. Остаток перегоняли в вакууме.

Получено 7,8 г фарнезола (выход 35\%) с т. кип. $122-125^{\circ}$ $(2 \mathrm{MM}), n_{D}{ }^{20} 1,4891, d_{4}{ }^{20} 0,8895$.

Найдено \%: $\mathrm{C}_{15} \mathrm{H}_{25} \mathrm{OH}$ (фталированием в пиридине).

\section{4. Методика газохроматографического анализа полученных продуктов}

Анализы были проведены на газовом хроматографе «Хром-1». Для анализа образцов гераниола применялась медная колонка диаметром 2,5 мм и длиной 11 , наполненная $0,5 \%$ полиэтиленгликоля 4000 на хромосорбе $W$ (30-60 меш). Рабочая температура колонки 140 , испарителя $150^{\circ}$. Газ-носитель $\mathrm{CO}_{2}$, скорость потока $15 \mathrm{~m} /$ мин, давление на входе 2,4 атм. Вытяжка пробы около 0,5 мкл. Для анализа образцов фарнезола применялась колонка длиной 2 м, наполненная $7 \%$ полиэтиленгликоля на хромосорбе $\mathbb{W}$. Рабочая температура $180^{\circ}$.

\section{Выводы}

1. Проверен метод получения чистого гераниола из продукта теломеризации изопрена с его гидрохлоридами селективным превращением 
содержащегося в нем геранилхлорида в соединение с диметиланилином, с последующим переводом последнего в геранилацетат.

2. Разработан метод получения аналогичным способом фарнезола из фракции сесквитерпеновых хлоридов.

3. Изучен изомерный состав образца синтетического фарнезола с помощью газовой хроматографии.

\title{
Л И Т Е Р А Т Р А
}

1. Л ээт с К. В., Авт. свид. № 128860, 1959; Бюлл. изобр., № 14, 1960.

2. Лээт с К. В., Авт. свид. № 130042, 1959; Бюлл. изобр., № 14, 1960.

3. Лээтс К. В., ЖОХ, 28, 1823 (1958), ЖОХ, 28, 3096 (1958).

4. Л ээ тс К. В., Эр м А., Изв. АН ЭССР, Сер. физ.матем. и техн. наук, 13, № 1, 57 (1964).

5. Gildemeister L., Hoffma nn Fr., Die Atherische Öe. Bd. IIIa, Berlin, 1960. S. 561 .

6. Шв арц Е. Ю., Петров А. А., ЖОХ, 32, 3278 (1962).

7. Л ээтс К. В., ЖОХ, 31, 1869 (1961).

8. Ruži cka L., Firmen ish G., Helv. 22, 392 (1939).

9. B ates R., Gale D., Gruner B., J. Org. Chem., 28, 1086 (1963).

\author{
Институт химии \\ Академии наук Эстонской ССР \\ Поступила в редакцию \\ 11/IV 1968
}

\section{K. LĀATS, A. KOGERMAN \\ GERANIOOLI JA FARNESOOLI SUNTEES ISOPREENI JA TEMA HODROKLORIIDIDE TELOMERISATSIOONIPRODUKTIDEST}

Uuriti geraniooli ja farnesooli süriteesimise võimalusi isopreeni ja tema hüdrokloriidide telomerisatsiooniproduktidest. Saadud tulemuste pöhjal töötati välja metoodika nimetatud ühendite sünteesimiseks. Gaasikromatograafilisel meetodil määrati sünteetilise farnesooli stereokeemiline koosseis.

\section{K. LÄÄTS, A. KOGERMAN \\ PREPARATION OF GERANIOL AND FARNESOL FROM THE TELOMERIZATION PRODUCTS OF ISOPRENE WITH ITS HYDROCHLORIDES}

In this paper the possibility has been studied of synthesizing geraniol 'and farnesol from the telomerization products of isoprene with its hydrochlorides. On the basis of the results obtained, a method has been elaborated for synthesizing the above-mentioned compounds. The stereochemical composition of synthetic farnesol has been determined by the gas chromatographic method. 